REVISTA DE GESTÃO ESECRETARIADO

MANAGEMENT AND ADMINISTRATIVE

PROFESSIONAL REVIEW

ISSN: 2178-9010
Revista GeSec

São Paulo, SP, Brasil

v. 12, n. 3, p. $1-18$

set./dez. 2021

DOI: http://dx.doi.org/10.7769/gesec.v12i3.1213

\title{
As dificuldades de percurso das mulheres empreendedoras
}

\section{The path difficulties of women entrepreneurs}

\author{
Larissa Lima Bandeira ${ }^{1}$ \\ Rafael Fernandes de Mesquita ${ }^{2}$ \\ Maria Kélvia Ferreira de Araújo ${ }^{3}$ \\ Fátima Regina Ney Matos ${ }^{4}$
}

\section{Resumo}

O aumento no número de empresas criadas por mulheres vem ganhando destaque nos últimos anos. De acordo com o Global Entrepreneurship Monitor, 50,7\% das mulheres concordaram que o medo de fracassar não as impediria de começar um novo negócio. Mas não é só o medo que deve ser enfrentado por elas. Outras dificuldades para a atividade empreendedora são apontadas na literatura, como: barreiras de gênero, conflito família e trabalho, financeiras, de apoio familiar, de gerência de negócio, disponibilidade de tempo e qualificação. Este artigo objetivou analisar as dificuldades enfrentadas pelas mulheres no desenvolvimento empreendedor na cidade de Campo Maior - PI. Optou-se por utilizar uma abordagem qualitativa e de cunho descritivo. As mulheres pesquisadas são jovens com idade entre 22 e 34 anos, com formação concluída ou em cursos de graduação em outras áreas, que não a de gestão, que resolveram empreender pela percepção de oportunidade. A realidade empreendedora das mulheres na cidade se aproxima da caracterização sintetizada a partir da leitura, à exceção da captação de recursos financeiros que não aparentou ser influenciada por barreiras de gênero.

Palavras-chaves: Empreendedorismo. Mulheres Empreendedoras. Gênero.

\begin{abstract}
The increase in the number of companies created by women has been gaining prominence in recent years. According to the Global Entrepreneurship Monitor, 50.7\% of women agreed that the fear of failure would not prevent them from starting a new business. But it is not just fear what they must face. Other difficulties for the entrepreneurial activity are pointed out in the literature, such as gender barriers, family and work conflict, financial, family support, business management, time availability, and qualification. This article aimed to analyze the difficulties women face in entrepreneurial development in Campo Maior-PI. It was decided to use a qualitative and descriptive approach. The women surveyed are young people aged between 22 and 34, with completed training or undergraduate courses in other

\footnotetext{
${ }^{1}$ Bacharela em Administração de Empresas.

2 Doutor em Administração de Empresas, Docente no Programa de Pós-graduação em Políticas Públicas da Universidade Federal do Piauí (UFPI).

${ }^{3}$ Bacharela em Administração de Empresas.

${ }^{4}$ Doutora em Administração de Empresas, Docente no Instituto Superior Miguel Torga (ISMT)/Coimbra-Portugal.
} 
areas, other than management, who decided to undertake due to the perception of opportunity. The entrepreneurial reality of women in the city comes close to the characterization synthesized from reading, except for capturing financial resources that did not appear to be influenced by gender barriers.

Keywords: Entrepreneurship. Entrepreneurial Women. Gender.

\section{Introdução}

O número de empresas criadas por mulheres vem ganhando destaque nos últimos anos. Desde o ano de 2000, o Global Entrepreneurship Monitor (GEM) realiza pesquisas anuais e revela as características marcantes do empreendedorismo brasileiro. Um estudo feito pelo GEM (2013) mostrou que esse foi o primeiro ano em que o número de novas empreendedoras mulheres superou o de homens, índice que não se repetiu no ano de 2018. Mesmo com uma diferença pequena, de $6,1 \%$, os homens se mostraram mais ativos que as mulheres no desenvolvimento de novos negócios. Esses dados corroboram a luta feminina na tarefa difícil de manterem-se no empreendedorismo. Cruz e Moraes (2013) informam que, embora mulheres empreendedoras possam apresentar alguns atributos positivos que auxiliam o desenvolvimento ou criação dos negócios, muitas dessas características podem desaparecer em condições adversas e pressões extremas. De acordo com a GEM (2019), 50,7\% das mulheres concordaram que o medo de fracassar não as impediria de começar um novo negócio. Por outro lado, $61,4 \%$ dos homens afirmaram isso. As mulheres se mostram mais inseguras nas tomadas de decisão. Quando questionadas se possuem conhecimento, habilidade e experiência necessárias para iniciar um novo negócio, 49,2\% das mulheres concordaram que possuem, contra 59,5\% dos homens.

Com a grande relevância das mulheres à frente das empresas e como forma de valorizálas, o SEBRAE criou em 2004 o prêmio SEBRAE mulher de negócios (PSMN). Em estudo no ano de 2018, divulgado em março de 2019, com objetivo de identificar o perfil das mulheres empreendedoras no Brasil, o SEBRAE (2019) concluiu que o país tem a $7^{\text {a }}$ maior proporção de mulheres entre os Empreendedores Iniciais e que elas têm uma proporção maior de negócios motivados por necessidade, que pode ser justificado pela dificuldade de se manter no mercado de trabalho e também porque não encontram soluções interessantes de ocupação e renda. Barone e Zouain (2019) fundamentam esses dados afirmando que muitas mulheres, diante da precariedade de espaços profissionais, onde possam empenhar sua força de trabalho e da crescente desigualdade, empregam seu conhecimento em atividades autônomas.

Com base nestes pressupostos, além de outros que são discutidos nas seções seguintes, em um ambiente de negócios majoritariamente masculino, uma mulher enfrenta várias 
dificuldades na luta pela igualdade de gênero e reconhecimento. Dentre as adversidades, sofrese com a falta de apoio familiar, inclusive dificuldade de aceitação, o que pode gerar uma consequência com problemas de autoconfiança. Esta batalha surge como uma forma de enfrentamento ao que era visto como empreendedorismo tradicional, representado por homens com conceitos e regras conduzidos por eles. Desta forma, a fim de compreender esse espectro composto por obstáculos, esse artigo objetivou analisar as dificuldades enfrentadas pelas mulheres no desenvolvimento empreendedor na cidade de Campo Maior - PI.

Esta pesquisa se mostra relevante devido ao crescente número de mulheres empreendedoras e à importância delas no mercado de trabalho, economia, renda, geração de emprego e também ao fortalecimento da luta feminina pela igualdade de gênero e o importante papel da mulher dentro da sociedade. É relevante, neste sentido, investigar as dificuldades enfrentadas pelas mulheres na abertura do seu próprio negócio, seu desempenho como forma de enfrentar tais conflitos e as motivações que levam a empreender. A escolha da cidade de Campo Maior, no estado do Piauí, se deu pela ausência de outros estudos com a mesma finalidade desenvolvidos no local, além de ser uma cidade com presença marcante de lojas e fábricas de roupas lideradas por mulheres.

\section{Referencial Teórico}

A criação de empresas representa o início do processo empreendedor, mas a perspectiva processual do empreendedorismo requer também a compreensão do crescimento, assim como da sobrevivência ou não do empreendedorismo (Gazola, Guedes \& Machado, 2017). Dessa forma, empreender possui uma gama de conceitos, sendo relevante reconhecer que há problemas e obstáculos a serem superados, por meio da percepção de uma oportunidade para mudança, a qual deve estar aliada a um novo processo de aprender (Teixeira, Andrade, Castro Alcântara \& Oliveira,2019). Para Schumpeter (1997), empreender envolve realizar coisas novas, empregando o talento a fim de tirar proveito das oportunidades. Neste processo, o empreendedor se depara com o risco, assumindo-o. Teixeira et al. (2019) corroboram com esse pensamento afirmando que a pessoa empreendedora tem como função formular ou modificar um método ou maneira existente, podendo até então criar algo novo, e que os mesmos são dotados de atitudes inteligentes, sabem definir objetivos a serem alcançados e visualizar oportunidades.

Segundo Bomfim e Teixeira (2015), o ambiente de negócios no Brasil melhorou muito na última década e o empreendedorismo é uma opção real de ocupação e renda para milhões de 
pessoas. $\mathrm{O}$ ato de empreender não ocorre apenas em momento de oportunidade, mas também em ocasiões de necessidade (Cararo, Becker, Guimarães \& Severo, 2018). O processo de busca do empreendedorismo por necessidade vem impulsionado pela manutenção da sobrevivência, já que se recolocar no mercado de trabalho pode ser uma busca difícil. Nessa mesma perspectiva de motivação empreendedora, de acordo com dados do GEM (2019), a maior taxa de busca da criação de empresas ainda é por oportunidade, e que vem aumentando gradativamente, chegando a $62 \%$ em 2018 .

Dentro do campo de pesquisa sobre empreendedorismo, os resultados apontam que a atuação de mulheres no papel empreendedor tem aumentado não apenas no Brasil, mas no mundo todo (Gouvêa, Silveira \&Machado, 2013). Cresce a cada ano o número de mulheres que tem buscado criar seu próprio negócio como forma de alavancar sua renda e serem mais independentes (Silva, El-Aouar, Silva \& Sousa, 2019). De acordo com uma pesquisa feita pelo GEM (2019) no Brasil, os homens se mostram mais ativos no que se refere ao seu envolvimento com o empreendedorismo, tanto no inicial quanto no estabelecido. No empreendedorismo estabelecido, a diferença entre homens e mulheres é de $6,1 \%$ e no inicial os homens registram uma taxa superior em 1,2\%, apresentando um total de $18,5 \%$ e as mulheres de $17,3 \%$.

A despeito da relevância da participação feminina, empreender, para elas, não tem sido uma tarefa fácil (Ferreira \& Nogueira, 2013), Alperstedt, Ferreira e Serafim (2014) conectam as dificuldades enfrentadas pelas mulheres à construção histórica do gênero feminino, somando dificuldades extras ao empreenderem, quando comparadas aos homens. E, apesar da compreensão social ter avançado no entendimento da importância do trabalho feminino e de haver perspectivas incentivadoras à atividade empreendedora feminina, é possível notar que a maior parte dos estudos sobre a temática ainda não problematiza - e até mesmo naturaliza - a desigual distribuição de poder entre homens e mulheres (Figueiredo et al., 2015).

O campo de estudo do empreendedorismo de mulheres é relativamente novo e se reveste de muita complexidade. $\mathrm{O}$ acentuado crescimento das empreendedoras, enquanto agentes no contexto socioeconômico, é mais que um dado estatístico: é o resultado histórico de um processo evolutivo de quebra de paradigmas e preconceitos que até hoje se faz presente (Almeida, Antonialli \& Gomes, 2011). Para Strobino e Teixeira (2014), é preciso lembrar que o gênero feminino ainda é associado ao trabalho doméstico e é perceptível que as mulheres continuam a desempenhar a maior parte desse trabalho, em particular as tarefas tidas como tipicamente femininas. Assim, como consequência de um processo de aceitação, que muitas vezes é desgastante para as mulheres, acaba se gerando uma desmotivação dentro de seu próprio negócio, tornando a experiência empreendedora tensa e negativa.

Revista Gestão e Secretariado (GeSec), São Paulo, SP, v. 12, n. 3, set./dez., 2021, p. 1-18. 
Identifica-se que a atividade empreendedora feminina sofre a influência de questões de gênero, quais sejam: a postura submissa da mulher, que repercute a formação dos papéis de gênero na "família tradicional"; a falta de credibilidade da atividade empreendedora feminina, e a reprodução das normas sociais que privilegiam a iniciativa empreendedora dos homens, por parte da própria mulher empreendedora (Figueiredo \& Mesquita, 2016). O que podemos constatar é que, apesar das transformações sociais no mundo moderno, as expectativas da sociedade em relação aos papéis masculinos e femininos mudaram muito pouco ao longo do tempo, moldando a relação entre a satisfação na carreira e o conflito família e trabalho. Diferentemente dos homens, que frequentemente tendem a priorizar suas carreiras, as mulheres costumam fixar prioridades para suas famílias que não dependem das responsabilidades profissionais (Lindo, Cardoso, Rodrigues \& Wetzel,2007).

O processo de empreender já é dotado de dificuldades e entraves que se colocam ao empreendedor. Ao falar de mulheres, Teixeira e Bonfim (2016) reconhecem que as empreendedoras enfrentam dificuldades extras, ao tentar conciliar a sua empresa com a família, na tentativa de equilibrar bem os seus múltiplos papéis, essas mulheres, muitas vezes, se deparam com a frustração e sentimento de culpa. O equilíbrio entre família e trabalho é visto como uma barreira para o sucesso de mulheres empreendedoras, mas que para algumas empreendedoras a família se torna um ponto de apoio e motivação (Araújo, Mesquita \& Matos, 2020). Percebe-se que a busca pelo ponto de equilíbrio entre as demandas conflitantes gera desgaste emocional e/ou físico. Segundo Alperstedt, Ferreira e Serafim (2014), destacam-se, como dificuldades encontradas no processo empreendedor, a percepção da falta de confiança nelas depositada e o conflito pessoal, familiar e empresarial, sendo estas últimas dimensões conflitantes na vida dessas mulheres, pois concorrem por sua atenção. São apontados, ainda, aspectos relativos à gerência do negócio, sendo as questões financeiras e as de mercado as mais graves.

O desafio de balancear o trabalho e a família é fonte de estudo para alguns autores. Para Strobino e Teixeira (2014), são raras as empreendedoras que têm a fronteira entre o trabalho e a vida pessoal, ou a vida em família, bem definida e, como consequência, o conflito trabalhofamília é defrontado. Neste sentido, Cavazotte, Oliveira e Paciello (2013) consideram dois constructos diferentes, mas interrelacionados: o conflito trabalho-família que ocorre quando as responsabilidades profissionais interferem no cumprimento das obrigações familiares, e o conflito família-trabalho quando obrigações relacionadas à família prejudicam o desempenho no trabalho. Eles compreendem que o entendimento dessas relações é importante para que as empresas tenham um equilíbrio favorável desses dois universos. Desse modo, é relevante que 
se tenha uma diferença entre trabalho e família, para que não existam conflitos entre ambos e, como consequência, ter um bom desenvolvimento organizacional.

Outro desafio que se destaca na atividade empreendedora das mulheres é a dificuldade de financiamento. Em um estudo feito por Barros, Palhano e Machado (2003) percebe-se que a dificuldade para obter recursos financeiros está entre as principais encontradas e, para superar esse problema, elas buscam a ajuda da família e amigos, especialmente do marido, que, na maioria dos casos, se revelou mais importante que os próprios sócios. Em adição a isso, as mulheres também apresentam dificuldades decorrentes de sua falta de experiência como empreendedoras, medo do risco financeiro e da dívida, falta de modelo e o baixo nível de assistência (Alperstedt, Ferreira \& Serafim, 2014), isso porque mulheres empreendedoras iniciantes tendem a apresentar características como a aversão ao risco e pouca experiência em gestão, além de enfrentarem dificuldades para conseguir financiamentos (Araújo et al., 2020).

Além das dificuldades familiares, as mulheres enfrentam barreiras associadas com a preparação de empreendedoras (Machado, Gazola, Fabricio \& Anez, 2016). Estudo feito por Gazola, Guedes e Machado (2017) corroboram o argumento da falta de qualificação, falta de autoconfiança e perfil não inovador como fatores que dificultam o desenvolvimento da atividade empreendedora. A inserção da mulher em alguns setores de atuação, tidos como carreiras masculinas, também é apresentada como um óbice à atividade empreendedora (Alperstedt, Ferreira \& Serafim, 2014). Outra dificuldade apontada na literatura, segundos os autores, diz respeito à desvantagem sentida no tocante às fontes dos recursos, quando muitas mulheres recorrem ao marido como fonte de recurso, apoiando e financiando sua ideia. Com isso, as mulheres sentem-se desmotivadas, pois nem sempre elas têm o apoio familiar e vão à busca de outras formas de viabilizar seus negócios.

Lindo et al. (2007) destacam que uma das principais razões para que a mulher tenha o próprio negócio é a flexibilidade de horários, que se justifica na liberdade que sentem em administrar seu tempo de acordo com as necessidades, principalmente as familiares, mesmo que para isso tenham de trabalhar mais e fora dos horários convencionais. Essa afirmação é ratificada por um estudo feito que, segundo Teixeira e Bomfim (2016), conclui que essas mulheres optaram pela atividade empreendedora em razão da flexibilidade e autonomia que esta proporciona e por fatores motivacionais relacionados não à necessidade, mas sim a uma estratégia deliberada, buscando conciliar as demandas familiares com o trabalho. Verificou-se, ainda, que elas tendem a ser muito envolvidas psicologicamente com o trabalho, mantendo uma relação de "amor profundo", além de dependerem de muitas horas por se sentirem responsáveis pelo sucesso ou fracasso do negócio.

Revista Gestão e Secretariado (GeSec), São Paulo, SP, v. 12, n. 3, set./dez., 2021, p. 1-18. 
Dados obtidos do GEM (2019), juntamente com o SEBRAE, corroboram que as empresárias se capacitam mais que os homens, mas que ainda existe uma pressão cultural para que sejam as responsáveis pelo lar e pelos cuidados com a família. A pesquisa mostra que, no Brasil, em 2017, as mulheres se dedicaram aos cuidados de pessoas e afazeres domésticos, aproximadamente, $73 \%$ mais horas que os homens. Com isso, as empreendedoras acabam se dedicando a seus negócios em tempo parcial, com um dado identificado de $30 \%$ a menos de dedicação que os homens.

Araújo, Gomes e Santana (2009) afirmam que os problemas que comprometem o êxito da empresa das empresas dirigidas por mulheres foram relacionados às dificuldades financeiras, falta de capacitação empreendedora e gerencial, restrições de mercado e distribuição, limitação de oportunidades e de participação em redes, baixo apoio governamental e institucional, ausência de know-how e de mecanismos de integração e até de corrupção em alguns países. Por outro lado, Gazola, Guedes e Machado (2017) reforçam em seus estudos que as empreendedoras se sobressaem positivamente no desenvolvimento de suas atividades, pois se dedicam muito tempo aos seus negócios, têm conhecimento sobre o negócio desde o início, são criativas e inovadoras, diversificando novos produtos e serviços.

A Figura, a seguir, apresenta o resultado da síntese da discussão proposta nesta seção, que possibilitou a organização das principais dificuldades listadas nas literaturas brasileira e internacional acerca do empreendedorismo de mulheres.

\begin{tabular}{|c|c|c|}
\hline Dificuldades & Breve descrição da dificuldade & Fontes \\
\hline $\begin{array}{l}\text { Barreiras de } \\
\text { gênero }\end{array}$ & $\begin{array}{l}\text { Obstáculos sociais para entrada em carreiras } \\
\text { tipicamente masculinas. Construção histórica dos } \\
\text { papéis sociais da mulher na sociedade. Naturalização } \\
\text { da desigualdade histórica de poder entre homens e } \\
\text { mulheres. }\end{array}$ & $\begin{array}{l}\text { Alperstedt, Ferreira e Serafim } \\
\text { (2014), Figueiredo et al. (2015), } \\
\text { Ferreira e Nogueira (2013) e } \\
\text { Strobino e Teixeira (2014) }\end{array}$ \\
\hline $\begin{array}{l}\text { Conflito família e } \\
\text { trabalho }\end{array}$ & $\begin{array}{l}\text { As mulheres costumam fixar prioridades para suas } \\
\text { famílias. A busca de equilíbrio gera desgaste } \\
\text { emocional e físico. As responsabilidades } \\
\text { profissionais interferem no cumprimento das } \\
\text { obrigações familiares e as obrigações relacionadas a } \\
\text { família prejudica no trabalho. Pressão cultural para } \\
\text { que sejam responsáveis pelo lar e família. }\end{array}$ & $\begin{array}{l}\text { Lindo et al. (2007), Teixeira e } \\
\text { Bomfim (2016), Cavazotte, } \\
\text { Oliveira e Paciello (2013) e } \\
\text { GEM (2018) }\end{array}$ \\
\hline $\begin{array}{l}\text { Recursos } \\
\text { Financeiros }\end{array}$ & $\begin{array}{l}\text { Obter financiamento. Falta de capital inicial. Falta de } \\
\text { fonte de recurso. }\end{array}$ & $\begin{array}{l}\text { Barros, Palhano e Machado } \\
\text { (2003), Machado et al. (2016) e } \\
\text { Alperstedt, Ferreira e Serafim } \\
(2014)\end{array}$ \\
\hline Apoio familiar & $\begin{array}{l}\text { Falta de apoio familiar e dificuldades devido } \\
\text { crianças pequenas. Sentimento de desmotivação, } \\
\text { fazendo com que busquem outra forma de viabilizar } \\
\text { seu negócio. }\end{array}$ & $\begin{array}{l}\text { Machado et al. (2016) e } \\
\text { Alperstedt, Ferreira e Serafim } \\
(2014)\end{array}$ \\
\hline $\begin{array}{l}\text { Gerência de } \\
\text { negócios }\end{array}$ & $\begin{array}{l}\text { Questões financeiras e de mercado. Falta de } \\
\text { experiência como empreendedoras, medo do risco } \\
\text { financeiro e da dívida, falta de modelo e o baixo }\end{array}$ & $\begin{array}{l}\text { Alperstedt, Ferreira e Serafim } \\
\text { (2014) e Machado et al. (2016) }\end{array}$ \\
\hline
\end{tabular}




\begin{tabular}{|c|l|l|}
\hline & $\begin{array}{l}\text { nível de assistência. Barreiras de preparação para } \\
\text { empreendedoras. }\end{array}$ & \\
\hline Tempo & $\begin{array}{l}\text { Falta de tempo. Falta de tempo para participações em } \\
\text { redes de networks. Buscam flexibilidade e } \\
\text { autonomia. }\end{array}$ & $\begin{array}{l}\text { Machado et al. (2016) e Teixeira e } \\
\text { Bomfim (2016) }\end{array}$ \\
\hline Qualificação & $\begin{array}{l}\text { Falta de qualificação e perfil não inovador. Falta de } \\
\text { acesso a informações comerciais. 30\% de dedicação } \\
\text { menos que os homens. }\end{array}$ & $\begin{array}{l}\text { Machado et al. (2016) e GEM } \\
\text { (2018) }\end{array}$ \\
\hline
\end{tabular}

Figura 1. Síntese das Dificuldades do Empreendedorismo de Mulheres

Fonte: Elaborado pelos autores (2020)

\section{Metodologia}

Considerando as características do objeto de estudo, optou-se por utilizar uma abordagem qualitativa (Mesquita \& Matos 2014). A abordagem qualitativa tem como características, segundo Merriam (1998): o pesquisador como principal instrumento de coleta de dados e de sua análise; esta abordagem usualmente envolve a pesquisa em campo empírico; primeiramente se emprega a estratégia de indução, em que se constroem abstrações, conceitos, hipóteses ou teorias, preferencialmente a testar teorias existentes; o produto resultado de uma pesquisa deste tipo é ricamente descritivo; é emergente e flexível, à medida que responde às mudanças de condições durante o progresso do estudo; a amostra selecionada é pequena, intencional; e o investigador desprende um longo período de tempo no campo em contato com o objeto investigado.

Nesse sentido, com o objetivo geral de compreender as dificuldades enfrentadas pelas mulheres no desenvolvimento empreendedor e, em adição, compreender como elas confrontam os desafios e mantém-se no mercado, foi feita uma pesquisa descritiva (Collis \& Hussey, 2005), que nos propõe a descrever os relatos das empreendedoras e as dificuldades enfrentadas por elas. A técnica de coleta de dados foi a entrevista. A entrevista foi conduzida a partir de um roteiro semiestruturado, um modelo considerado por Mattos (2010) como uma forma especial de conversação. A entrevista semiestruturada é uma técnica utilizada frequentemente para obtenção de informações, conduzida por um roteiro de questões, sendo um método mais espontâneo, em que o entrevistador conduz com perguntas já preestabelecidas.

Foram realizadas entrevistas com mulheres empreendedoras que atuam na cidade de Campo Maior - PI, entre os meses de abril e maio de 2020, por meio de ligação telefônica, respeitando as recomendações da Organização Mundial de Saúde durante a pandemia da COVID-19. As conversas foram gravadas e possuem duração média de trinta minutos.

A cidade foi escolhida por conta da presença de grandes fábricas de roupas e lojas lideradas por mulheres e pela ausência de estudos com a mesma finalidade na região. Campo 
Maior- PI é uma cidade localizada a 84km da capital do Piauí e, segundo o IBGE (2019), tem uma população estimada em 46.833 habitantes, caracterizando-se pela presença marcante da carnaúba. Sua economia está baseada principalmente na atividade comercial, agricultura, pecuária e extrativismo e é destaque também pelas grandes fábricas de roupas localizadas na cidade.

As participantes foram convidadas a participar da pesquisa e os critérios de inclusão delas neste estudo foram: possuir cadastro no MEI (Microempreendedor Individual), possuir acima de 2 anos de empresa, ter o empreendimento localizado no centro da cidade, lugar onde possui a maior concentração de lojistas. Foram excluídas da pesquisa aquelas que não concordarem em participar. O número de participantes foi definido por saturação teórica, quando as entrevistas não contribuírem em qualidade ou quantidade de informações com o conteúdo das respostas, permitindo a observação de reincidências de resposta (Minayo, 2017).

Após coleta, transcrição e organização dos dados, estes foram analisados a partir da técnica de análise de conteúdo (Bardin, 2010). A análise foi desenvolvida de acordo com as etapas sugeridas por Bardin (2010): 1) pré-análise, 2) exploração do material e 3) tratamento dos resultados, inferência e interpretação. Na pré-análise, a organização do material a ser analisado tem por objetivo torná-lo operacional, sistematizando as ideias preliminares. A exploração do material compreende a definição de categorias (sistemas de codificação) e a identificação das unidades de registro e das unidades de contexto nos documentos. No tratamento dos resultados ocorre a condensação e a ênfase das informações para análise, resultando nas interpretações inferenciais (Bardin, 2010).

\section{Análise e Discussão dos Resultados}

A partir da análise das entrevistas colhidas, percebe-se que as mulheres empreendedoras de Campo Maior-PI são jovens com idade entre 22 e 34 anos. A maioria tem formação ou estão em cursos de graduação em outras áreas, que não a de gestão. Das 8 entrevistadas, 3 são casadas e dessas, 2 possuem filhos. Outro elemento de destaque inicial é o que as levou à abertura de suas empresas, mostrando que a vontade de empreender (oportunidade) se sobressai entre a necessidade de ter seu próprio negócio, conforme pode ser observado na Tabela 1.

Tabela 01.

Características das empreendedoras 


\begin{tabular}{|c|c|c|c|c|c|c|c|}
\hline $\begin{array}{l}\text { Entre } \\
\text { vista }\end{array}$ & Idade & $\begin{array}{l}\text { Estado } \\
\text { civil }\end{array}$ & Filhos & Formação & Segmento & Tempo & $\begin{array}{l}\text { Empreendeu } \\
\text { por }\end{array}$ \\
\hline 1 & 22 anos & Solteira & Não & Administração & Cosméticos & 4 anos & Oportunidade \\
\hline 2 & 34 anos & Solteira. & Não & $\begin{array}{c}\text { Fonoaudiologia } \\
\text { e Odontologia }\end{array}$ & $\begin{array}{l}\text { Moda } \\
\text { feminina }\end{array}$ & 15 anos & Oportunidade \\
\hline 3 & 28 anos & Solteira. & Não & Moda & $\begin{array}{c}\text { Moda } \\
\text { feminina }\end{array}$ & 4 anos & Necessidade \\
\hline 4 & 25 anos & Solteira & Não & Direito & Estética & 10 anos & Oportunidade \\
\hline 5 & 28 anos & Casada & Sim & Radiologia & Cosméticos & 7 anos & Necessidade \\
\hline 6 & 28 anos & Solteira & Não & Nutrição & Alimentos & 6 anos & Oportunidade \\
\hline 7 & 25 anos & Casada & Sim & Enfermagem & $\begin{array}{c}\text { Moda } \\
\text { feminina }\end{array}$ & 5 anos & Necessidade \\
\hline 8 & $\begin{array}{l}\text { Idade não } \\
\text { revelada }\end{array}$ & Casada & Não & Nutrição & $\begin{array}{c}\text { Produtos } \\
\text { naturais e } \\
\text { suplementa } \\
\text { ção }\end{array}$ & 6 anos & Oportunidade \\
\hline
\end{tabular}

Fonte: Elaborado pelos autores (2020).

O processo de empreender já é dotado de dificuldades e entraves que se colocam ao empreendedor. Ao falar de empreendedorismo de mulheres é preciso reconhecer que elas enfrentam dificuldades extras, ao tentar equilibrar bem os seus múltiplos papéis sociais (Teixeira \& Bomfim, 2016). As entrevistadas responderam um total de 13 perguntas envolvendo 7 categorias relacionadas às dificuldades do empreendedorismo de mulheres (Quadro 1), das quais se têm: barreiras de gênero, conflito família e trabalho, financeiro, apoio familiar, gerência de negócio, tempo e qualificação.

Quando perguntadas se perceberam algumas dificuldades de entrada no mercado de trabalho, que pode ser um fator motivador ao início de negócios, também na abertura de empresa por ser mulher, as entrevistadas chamaram atenção para o preconceito sofrido por serem mulheres e jovens. A exceção foi a entrevistada 7 que pontuou não perceber dificuldades quanto ao gênero. Figueiredo e Mesquita (2016) entendem que a falta de credibilidade enfrentada por mulheres se dá por conta da reprodução de normas sociais que privilegiam a iniciativa empreendedora dos homens.

Sim, às vezes eu acho que nem todo mundo tem tanta credibilidade por ser mulher e por ser jovem. Acho que gera um pouco de preconceito. (Entrevistada 1)

A nossa sociedade ainda é bem preconceituosa em alguns quesitos, dependendo de qual seja a área que a mulher deseja atuar ela sofre algum tipo de preconceito. (Entrevistada 4)

A dificuldade que eu senti foi não só apenas por ser mulher, mas por ser uma jovem mulher. (Entrevistada 6) 
Não eu não percebo nenhuma dificuldade por conta de ser mulher, acho que nos dias dos atuais não existe mais esse problema em relação ao gênero. (Entrevistada 7)

Percebo sim, uma certa dificuldade. Porque o mundo ainda é muito machista e com isso as pessoas acabam que não 'colocando fé'. (Entrevistada 8)

Elas afirmaram que mulheres empreendedoras sofrem com as dificuldades alinhadas às disparidades sociais do gênero e que elas percebem essa dificuldade. A idade se destaca dentro das falas das entrevistadas 1 e 6 que afirmam que, quando alinhada ao gênero, amplifica os obstáculos percebidos. Entende-se como barreira de gênero os obstáculos sociais para entrada em carreiras tipicamente masculinas, construção histórica dos papéis sociais da mulher na sociedade e a naturalização da desigualdade histórica de poder entre homens e mulheres (Ferreira \& Nogueira, 2013; Alperstedt, Ferreira \& Serafim, 2014; Strobino \& Teixeira, 2014; Figueiredo et al., 2015).

Nesta mesma categoria, as empreendedoras responderam quais os papéis atribuídos à mulher na sociedade atual e se isto atrapalha ou ajuda a conseguir um emprego. Segundo elas, as mulheres estão, cada vez mais, conquistando seu espaço. Porém, ainda há alguns entraves, como o estado civil e os filhos, o que pode ser observado nos trechos:

\footnotetext{
Em entrevistas que perguntam se 'você' é casada, se 'você' tem filhos, pra alguns isso é bem-visto e para alguns isso, às vezes, não é. Porque uma mulher que tem filhos, a criança pode adoecer e ela pode se afastar do trabalho, diferente da que não tem. (Entrevistada 2)

Muitas empresas alegam a questão da gravidez, que a mulher grávida vai dar mais despesa por conta da gravidez. (Entrevistada 4)

Antigamente, a mulher tinha um papel muito resumido na sociedade, era mãe de família e dona de casa, hoje a mulher pode ser isso e muito mais. [...] muitas empresas não admitem mulheres com filhos, porque demanda um pouco mais, e na hora da seleção acabam preferindo mulheres mais jovens, mulheres solteiras, isso é real. (Entrevistada 6)

Eu acredito que sim, porque ainda tem muitas empresas que não querem contratar pessoas que têm filhos. (Entrevistada 8)
}

$\mathrm{Na}$ visão das entrevistadas as mulheres têm uma diversidade de atribuições na sociedade, mas ainda existem "tabus" que dificultam sua entrada no mercado. A maternidade em si e a possibilidade da gravidez são vistas como obstáculos para a sua contratação. A percepção corrobora o argumento de que, diferentemente dos homens, que frequentemente tendem a priorizar suas carreiras, as mulheres são interpretadas como aquelas que fixam como prioridade as suas famílias (Lindo et al., 2007).

No que se refere a divisão das responsabilidades entre o trabalho e a família, entrevistadas afirmam que, quando se é casada e se têm filhos, se torna mais difícil conciliar as atividades. Até para a entrevistada 6, que é solteira e não possui filhos, quando vislumbra a possibilidade, afirma que seria difícil conciliar ambas as responsabilidades, uma vez que dedica cerca de 12 horas para sua empresa. A exceção foi a entrevistada 5 que, mesmo casada e com filho, afirmou não possuir conflitos nos encargos. Strobino e Teixeira (2014) afirmam serem 
raras as empreendedoras que têm a fronteira entre o trabalho e a vida pessoal, ou a vida em família, bem definida, e como consequência, geralmente o conflito trabalho-família é defrontado.

Creio que você empreender, sendo casada e tendo filhos, é mais difícil conciliar todas as suas atividades
para com sua família. Como também suas atividades profissionais. (Entrevistada 4)
Sou casada e tenho um filho. Não dificultou minha vida empreendedora, pelo contrário, melhorou muito,
me ajudou a pensar mais longe e pensar mais positivo, a ter uma visão mais ampla [...] sempre fazendo o
máximo que eu posso, tento ficar com meu filho e acompanhar de perto todas as fases dele. (Entrevistada
5)
Não sou casada e também não tenho filhos. Mas tenho certeza que se tivesse, isso dificultaria um
pouco na minha vida de empreendedora, porque passo mais de 12 horas trabalhando. (Entrevistada 6 )

As empreendedoras solteiras veem filhos como uma dificuldade, o que é confirmado pela entrevistada 7 , que relata a divisão de tarefas conflituosa. O equilíbrio entre família e trabalho é visto como uma barreira para o sucesso de mulheres empreendedoras (Araújo et al., 2020). Percebe-se que apenas a entrevistada 5 apresenta opinião diferente, e a família, para ela, é um fator motivador ao empreendedorismo (Araújo et al., 2020).

Os recursos financeiros, para qualquer empreendedor, são elementos importantes na abertura ou manutenção de um negócio. As perguntas foram relacionadas ao capital inicial de suas empresas, se elas já tinham recursos, quais meios precisaram recorrer e se sentiram dificuldades com as instituições financeiras. A seguir se apresentam algumas das respostas.

\footnotetext{
A gente não tinha nenhum recurso. Foi o jeito a gente vender um bem que a gente tinha. (Entrevistada 3)

Eu tive recursos, mas precisei recorrer também a outros meios. Senti um pouco de dificuldade porque minha empresa era nova, estava abrindo minha empresa, e eles precisam que você passe algum faturamento mensal da empresa e ela era bem nova. (Entrevistada 6)

No começo foi mais difícil porque não tínhamos a loja registrada e os bancos para conseguir empréstimo era mais difícil. (Entrevistada 7)

Eu não tinha recursos financeiros no primeiro momento. Quando pensei em colocar fui comprando aos poucos, cartão de crédito para pagar com um mês e apurar nas vendinha. (Entrevistada 8)
}

Elas relataram ter dificuldade com questões burocráticas como registro e pouco tempo de funcionamento de seus empreendimentos para conseguir empréstimos em bancos, tendo que recorrer ao cartão de crédito pessoal ou contar com suas vendas realizadas para manter seu capital de giro, mas não citam problemas de preconceito ou discriminação de gênero na obtenção de créditos. A literatura aponta que mulheres empreendedoras possuem dificuldades para captação de capital, sendo captação financeira um desafio enfrentado por elas (Alperstedt, Ferreira \& Serafim, 2014; Araújo et al., 2020).

Machado et al. (2016) afirmam que uma das dificuldades encontradas pelas empreendedoras é a falta de apoio familiar. Contudo, de todas entrevistadas, apenas a entrevistada 8 se sentiu desmotivada por não ter tido o apoio da mãe. As demais afirmaram ter 
apoio e incentivo no empreendedorismo e, no caso da entrevistada 7, o fato de possuir uma mãe empreendedora a ajudou.

Eu tive total apoio familiar, eu tenho sempre apoio familiar. Acho que por vir de família empreendedora, tanto do lado do pai como da minha mãe. (Entrevistada 6)

Eu sempre tive esse apoio porque minha mãe também tem loja e trabalha no mesmo segmento que o meu. (Entrevistada 7)

Minha mãe não queria, meu pai não intervia, meu esposo sempre me apoiou e meu irmão também. Então, me senti algumas vezes desmotivada, deu vontade de desistir pela falta de apoio da minha mãe. (Entrevistada 8)

Apesar da falta de apoio pela mãe, a entrevistada 8 afirmou possuir apoio por parte do marido. O apoio familiar se dá, muitas vezes, no apoio financeiro, especialmente pelos maridos que, na maioria dos casos, se revelou mais importante que os próprios sócios (Barros, Palhano \& Machado 2003). Possuir uma família empreendedora permitiu à entrevistada 6 maior apoio familiar.

Essa categoria é um ponto comum entre todas as empreendedoras pesquisadas. Elas afirmam a falta de experiência e conhecimentos em administração de empresas, ao iniciar a vida empresarial. Contudo, por outro lado, elas também declaram que buscam conhecimentos para suprir esta ausência. Outro elemento que esteve e permanece presente é o medo de empreender. Todas demonstraram medo para abrir seu próprio negócio, mencionando motivos como medo de falir, inseguranças e concorrência. O relato da entrevistada 8 resume bem o que todas quiseram dizer ao serem perguntadas de suas experiências e se a gerência de negócios lhes trouxera medo:

Eu não tinha experiência de nada, com o passar do tempo que eu fui fazendo cursos de administração, empreendedorismo, marketing. Sempre procurei me atualizar e com isso que me ajudou muito [...]Associo meu medo mais a essa questão da concorrência. A questão também de 'será que estou gerenciando bem?' 'será que estou tendo lucro suficiente?' 'cadê o dinheiro da empresa que eu não to vendo lucro?' 'será que estou no caminho certo?' 'será que posso melhorar?'. Então, tudo isso gera medo, desconforto e insegurança.

Mulheres empreendedoras iniciantes tendem a apresentar características como a aversão ao risco e pouca experiência em gestão (Araújo et al., 2020). O medo, desconforto e a insegurança relatados pela entrevistada 8 aparecem como uma consequência de não possuir experiência e receio de enfrentar a concorrência. Apesar das dificuldades e do medo, Gazola, Guedes e Machado (2017), reforçam em seus estudos que as empreendedoras se sobressaem positivamente, pois se dedicam muito tempo aos seus negócios, são criativas e inovadoras, diversificando novos produtos e serviços. 
As entrevistadas foram questionadas sobre como elas gerenciam o tempo delas na empresa. Elas responderam que dedicam até 12 horas por dia de trabalho, como é o caso das entrevistadas 3 e 6 .

Atualmente, eu acordo 7:00 horas da manhã e trabalho até 18:00 horas, eu só paro para almoçar meio dia, mas é só almoçar e volto de novo. Nas minhas horas vagas, estou na internet pesquisando tendência, pesquisando tudo enquanto que for voltado para o meu negócio. (Entrevistada 3)

Eu passo mais de 12 horas gerenciando, eu participo de todas as etapas na verdade. (Entrevistada 6)

Dados obtidos do GEM (2019), juntamente com o SEBRAE, mostram que ainda existe uma pressão cultural para que as mulheres sejam as responsáveis pelo lar e pelos cuidados com a família, o que faz com que as empreendedoras dediquem tempo parcial a seus negócios. Contudo, foi percebido que as empreendedoras pesquisadas dedicam a maior parte do seu dia às empresas, buscando participar de todas as etapas do gerenciamento do negócio.

$\mathrm{Na}$ categoria qualificação, o SEBRAE se mostra presente na vida dessas empreendedoras, assim como cursos de marketing e outros mencionados.

\footnotetext{
Assim, eu tenho amigas que trabalha no SEBRAE, eu fiz alguns cursos de marketing, fiz e faço, porque eu acho que todas as áreas que você vai seguir hoje, todo empreendimento é um comércio. (Entrevistada 2)

Fiz alguns cursinhos, não fiz especialização. No SEBRAE, eles sempre traziam cursos bacanas, fiz alguns online e outros presenciais. Sempre fui atuante e busquei me atualizar nessa área pra poder ajudar a empresa de todas as formas. (Entrevistada 6)

Sempre fiz cursos do SEBRAE, cursos em Teresina, workshop, feirinhas, sempre procuro me capacitar como também capacitar minhas atendentes. (Entrevistada 8)
}

Dados obtidos do GEM (2019), juntamente com o SEBRAE, informam que as empresárias se capacitam mais que os homens. É válido mencionar, como a entrevista 8 citou, a preocupação com a capacitação para funcionários.

\section{Conclusão}

Este artigo objetivou analisar as dificuldades enfrentadas pelas mulheres no desenvolvimento empreendedor na cidade de Campo Maior - PI. A realidade empreendedora das mulheres na cidade se aproxima da caracterização sintetizada a partir da leitura: como o sofrimento com as dificuldades alinhadas às disparidades de gênero na atividade, amplificada pela percepção externa da juventude das participantes, interpretada como falta de credibilidade e experiência. O conflito 'trabalho e família' ficou evidente na dificuldade de equilíbrio entre a gestão do negócio e o cuidado com os filhos. $\mathrm{O}$ apoio familiar foi apresentado como fator motivador. Os problemas de gestão foram associados à baixa qualificação técnica e ao medo do fracasso. E, em relação ao tempo de dedicação às atividades empresariais, os resultados 
apontam rotinas extensas. No entanto, em contraste com a literatura, a captação de recursos financeiros não aparentou ser influenciada por barreiras de gênero.

O que vai de encontro à literatura específica do empreendedorismo pode ser compreendido como um indício de uma mudança em direção à redução das dificuldades na obtenção de créditos financeiros para abertura e manutenção de negócios. Estes indícios podem ser investigados em pesquisas futuras que busquem confirmações desta mudança nas instituições financeiras ou com mulheres que procuraram financiamentos para suas empresas. Assim, sugere-se continuidade deste trabalho de pesquisa, em focar aspectos que não foram centrais na análise desenvolvida e, também, a partir da ampliação do alcance geográfico, que pode ser apontada aqui como um fator limitante. Outra possibilidade seria a proposição de um novo modelo de interpretação do fenômeno social do empreendedorismo mulheres, a partir de categorias empíricas, a posteriori, sem definição das dimensões de análise a priori, o que pode contribuir com o debate já estabilizado na literatura da temática.

Os resultados desta pesquisa contribuem com a literatura acadêmica sobre empreendedorismo a partir de um foco regional no nordeste brasileiro, em uma cidade afastada de grandes centros urbanos, facilitando a compreensão de como se desenvolve a atividade empreendedora de mulheres nestas regiões. Neste sentido, também contribui com a percepção social de que mulheres vêm transformando seus papéis de atribuição de gênero, encabeçando atividades empreendedoras que desenvolvem com apoio familiar, apesar de que sua participação na função de 'mãe' e 'dona de casa' ainda seja um empecilho evidente.

\section{Referências}

Almeida, I. C., Antonialli, L. M., \& Gomes, A. F. (2011). Comportamento estratégico de mulheres empresárias: estudo baseado na tipologia de Miles e Snow. Revista Ibero Americana de Estratégia, 10(1), 102-127.

Alperstedt, G. D., Ferreira, J. B., \& Serafim, M. C. (2014). Empreendedorismo feminino: dificuldades relatadas em histórias de vida. Revista de Ciências da Administração, 16(40), 221-234.

Araújo, M. K. F., Silva, R. L. S., de Mesquita, R. F., \& Matos, F. R. N. (2020). May That Nothing Limit Us, May That Nothing Define Us: The Context of Women Entrepreneurs in Startups. In: Handbook of Research on Approaches to Alternative Entrepreneurship Opportunities (pp. 395-409). IGI Global. 
Araújo, U. P.; Gomes, A. F.; Santana, W. G. P. (2009). Empreendedorismo Feminino: O Estado-da-arte. In: ENANPAD- Encontro Nacional da ANPAD, 33, São Paulo. Anais...RJ: ANPAD.

Bardin, L. (2010). Análise de conteúdo. Lisboa: Edições. Trad. Luís Antero Reto e Augusto Pinheiro. Lisboa: Edições 70 LDA.

Barone, F. M.; Zouain, D. M. (2019). Empreendedorismo feminino no Brasil: políticas públicas sob análise. RAP-Revista de Administração Pública. Rio de Janeiro. Jan./Fev.

Barros, G. V. D., Palhano, D. Y. M., \& Machado, H. V. (2003). Conhecendo a empreendedora norte paranaense: perfil, porte das empresas e dificuldades de gerenciamento. Caderno de Administração UEM, 11(1), 51-67.

Bomfim, L. C. S., \& Teixeira, R. M. (2015). Empreendedorismo feminino: desafios enfrentados por empreendedoras na gestão de pequenos negócios no setor de turismo. Revista Pensamento Contemporâneo em Administração, 9(2), 48-69.

Cararo, W. R., Becker, A., de Guimarães, J. C. F., \& Severo, E. (2018). Empreendedorismo e inovação como estratégia organizacional: Um caso de ensino. Revista Eletrônica de Administração e Turismo-ReAT, 12(7), 1736-1749.

Cavazotte, F. D. S. C. N., Oliveira, L. B \& Paciello, R. R. (2013). Antecedentes e consequências dos conflitos entre trabalho e família. Revista de administração contemporânea, 17(4), 418-437.

Cruz, M. T. S, \& de Moraes, I. M. M. (2013). Empreendedorismo e Resiliência: mapeamento das competências técnicas e comportamentais exigidas na atualidade. Pensamento \& Realidade, 28(2).

Ferreira, J. M., \& Nogueira, E. E. S. (2013). Mulheres e suas histórias: razão, sensibilidade e subjetividade no empreendedorismo feminino. Revista de Administração Contemporânea, 17(4), 398-417.

Figueiredo, M. D.; Machado, D. Q.; Matos, F. R. N.; Melo, A. N. (2015). Empreendedorismo feminino no artesanato: uma análise crítica do caso das rendeiras dos morros da Mariana. Revista Eletrônica de Ciência Administrativa, 14(2), 110-123.

Figueiredo, M. D.; Mesquita, R. F. (2016). A norma masculina do empreendedorismo e as possibilidades de emancipação feminina. In: Vieira, A.; Carrieri, A. P. (Org.). Gênero e saúde na dinâmica do trabalho: a saúde da mulher em foco. 1. ed. Curitiba: Juruá,177-198.

GEM - Global Entrepreneurship Monitor. Empreendedorismo no Brasil - 2013: relatório executivo. (2013). Curitiba: IBQP/SEBRAE. Disponível em: https://ibqp.org.br/wp- 
content/uploads/2017/07/GEM_2013_Livro_Empreendedorismo_no_Brasil.pdf.pdf. Acesso em: 10/09/2020.

GEM - Global Entrepreneurship Monitor. (2019). Empreendedorismo no Brasil - 2019: relatório executivo. Curitiba: IBQP/SEBRAE, 2019. Disponível em: https://ibqp.org.br/gem/. Acesso em: 10/09/2020.

Gouvêa, A. B. C. T., Silveira, A., \& Machado, H. P. V. (2013). Mulheres empreendedoras: compreensões do empreendedorismo e do exercício do papel desempenhado por homens e mulheres em organizações. Revista de Empreendedorismo e Gestão de Pequenas Empresas, 2(2), 32-54.

Hussey, R., \& COINS, J. (2005). Pesquisa em administração: um guia prático para alunos de graduação e pós-graduação. 2. ed. Porto Alegre: Bookman.

IBGE - Instituto Brasileiro de Geografia e Estatística. (2019). v4.3.46. Disponível em: https://cidades.ibge.gov.br/brasil/pi/campo-maior/panorama. Acesso em: 10/09/2020.

Lindo, M. R., Cardoso, P. M., Rodrigues, M. E., \& Wetzel, U. (2007). Vida pessoal e vida profissional: os desafios de equilíbrio para mulheres empreendedoras do Rio de Janeiro. RAC-Eletrônica, 1(1), 1-15.

Machado, H. P. V., Gazola, S., Fabricio, J. D. S., \& Anez, M. E. (2016). Women entrepreneurs: Reasons and difficulties for starting in business. RAM. Revista de Administração Mackenzie, 17(3), 15-38.

Machado, H. P. V., Guedes, A., \& Gazola, S. (2017). Determinantes e dificuldades de crescimento para mulheres empreendedoras. Revista Pensamento Contemporâneo em Administração, 11(1), 85-99.

Mesquita, R. F., \& Matos, F. R. N. (2014). A abordagem qualitativa nas ciências administrativas: aspectos históricos, tipologias e perspectivas futuras. Revista Brasileira de Administração Científica, 5(1), 7-22.

Mattos, P. L. C. L. (2010). Análise de entrevistas não estruturadas: da formalização à programática da linguagem. In: Silva, A. B.; Godoi, C. K.; Mello, R. DE B. (Org.). Pesquisa qualitativa em estudos organizacionais: paradigmas, estratégias e métodos. 2. ed. São Paulo: Saraiva.

Merriam, S. B. (1998). Qualitative Research and Case Study Applications in Education. Revised and Expanded from "Case Study Research in Education". Jossey-Bass Publishers, 350 Sansome St, San Francisco, CA 94104.

Minayo, M. C. S. (2017). Amostragem e saturação em pesquisa qualitativa: consensos e controvérsias. Revista Pesquisa Qualitativa, 5(7), 1-12. 
Schumpeter, J. A. (1997). A Teoria do Desenvolvimento Econômico. São Paulo: Nova Cultura. SEBRAE. Serviço de Apoio às Micros e Pequenas Empresas do Piauí. Empreendedorismo feminino no Brasil. (2019). Disponível em: https://www.sebrae.com.br/Sebrae/Portal\%20Sebrae/UFs/GO/Sebrae\%20de\%20A\%20a \%20Z/Empreendedorismo\%20Feminino\%20no\%20Brasil\%202019_v5.pdf. Acesso em: 20/08/2020.

Silva, P. M. M., El-Aouar, W. A., da Silva, A. W. P., \& de Sousa, J. C. (2019). A resiliência no empreendedorismo feminino. Gestão e Sociedade, 13(34).

Strobino, M. R.C., \& Teixeira, R. M. (2014). Empreendedorismo feminino e o conflito trabalhofamília: estudo de multicasos no setor de comércio de material de construção da cidade de Curitiba. Revista de Administração, 49(1), 59-76.

Teixeira, T. S., Andrade, D. M., de Castro Alcântara, V., \& de Oliveira, N. K. (2019). Inovação e Empreendedorismo: Um caso no setor público. Revista Pretexto, 20(1), 57-71.

Teixeira, R. M., \& Bomfim, L. C. S. (2016). Empreendedorismo feminino e os desafios enfrentados pelas empreendedoras para conciliar os conflitos trabalho e família: estudo de casos múltiplos em agências de viagens. Revista Brasileira de Pesquisa em Turismo, 10(1), 44-64.

Submetido em: 13.12 .2020

Aceito em: $\quad 21.04 .2021$ 